\title{
The NF-kB and Collagen Type 1 Expression in Dental Pulp after Treated Calcium Hydroxide Combined with Propolis
}

\author{
Nirawati Pribadi ${ }^{1}$ Dwita Budiarti ${ }^{2}$ Hendy Jaya Kurniawan² ${ }^{2}$ Ira Widjiastuti ${ }^{1}$ \\ 1Department of Conservative Dentistry, Faculty of Dental Medicine, \\ Address for correspondence Ira Widjiastuti, drg, MKes, SpKG(K), \\ Universitas Airlangga, Surabaya, Indonesia \\ ${ }^{2}$ Conservative Specialist Degree. Faculty of Dental Medicine. \\ Universitas Airlangga. Surabaya, Indonesia \\ Department of Conservative Dentistry, Faculty of Dental Medicine, \\ Universitas Airlangga,Surabaya 60132, Indonesia \\ (e-mail: ira-w@fkg.unair.ac.id).
}

Eur J Dent:2021;5:122-126

\begin{abstract}
Objective To analyze the expression of nuclear factor kappa B (NF-kB) and collagen type 1 on dental pulp after a treated combination of calcium hydroxide and propolis. Materials and Methods The first maxillary molars of 30 rats were mechanically perforated. Teeth were divided into three groups of 10 for two separate extraction time frames, giving a total of 60 rats. The control groups were treated with Cention, the second treatment groups were treated with calcium hydroxide, and the third treatment groups were treated with a combination of calcium hydroxide and propolis. Final restoration was done with Cention. The teeth were extracted on days 7 and 14 , and the expression of NF-kB and collagen type I was analyzed using immunohistochemistry.

Results There is lowest NF-kB expression and highest collagen type 1 expression on

Keywords

- calcium hydroxide

- propolis

- collagen type 1

$-\mathrm{NF}-\mathrm{kB}$ dental pulp after treated with a combination of calcium hydroxide and propolis on days 7 and $14(p<0.05)$.

Conclusion The combination of calcium hydroxide and propolis inhibits pulp inflammation and stimulates regeneration through decreasing the NF-kB expression and increasing collagen type 1 .
\end{abstract}

\section{Introduction}

In the pulp affected by inflammation, there are several mediators closely related to inflammatory reactions, one of which is cytokine. Cytokines function as intracellular signals that regulate the activity of immune response, local and systemic inflammation against outside stimuli. ${ }^{1}$ Nuclear factor kappa $\mathrm{B}(\mathrm{NF}-\mathrm{kB})$ is a transcription factor that can induce gene transcription factors from several proinflammatory cytokines associated with signal stimulation in cells caused by a pathogen or injury. NF-kB is a transcription factor that produces proinflammatory cytokines, which are the main target in pulp inflammation. ${ }^{2,3}$

As a response after pulp inflammation, dentin synthesis can be formed through the process of biomineralization. Collagen type 1 plays a crucial role in the biomineralization process and accounts for $90 \%$ of the total protein in the organic matrix of bone and dentin. Collagen not only provides the skeletal and dentinal skeletal structures with viscoelastic properties but also prepares the space for the mineral deposition process. Collagen type 1 induces the formation of hydroxyapatite crystals, which is the initial formation of reparative dentine, as part of pulp and dentine regeneration. ${ }^{4}$

Calcium hydroxide is the gold standard for direct pulp capping and has antibacterial properties due to its $\mathrm{pH}$ of 12.5 ; subsequently, it can damage or destroy cell membranes and bacterial protein structures. The effectiveness of calcium hydroxide depends on the dissociation and release of $\mathrm{OH}^{-}$ (hydroxyl ions), which penetrate tissues. The deficiency of calcium hydroxide affects the ability to form a necrotic layer and the process of forming a dentine reparative, producing

(C) 2021. European Journal of Dentistry.

This is an open access article published by Thieme under the terms of the Creative Commons Attribution-NonDerivative-NonCommercial-License, permitting copying and reproduction so long as the original work is given appropriate credit. Contents may not be used for commercial purposes, or adapted, remixed, transformed or built upon. (https://creativecommons.org/licenses/by-nc-nd/4.0/)

Thieme Medical and Scientific Publishers Pvt. Ltd., A-12, 2nd Floor, Sector 2, Noida-201301 UP, India 
a porous structure. This deficiency results in an imperfect dentine formation, ${ }^{3}$ appear as tunnel defect in the dentine structure and internal root resorption..$^{5}$ Some cases reported that $31.5 \%$ indirect pulp capping with calcium hydroxide has failure if compared with other material such as mineral trioxide aggregate (MTA). ${ }^{6}$

Based on previous research, propolis is an alternative material that can be used in pulp capping to reduce inflammation in exposed pulp. Propolis contains chemical compounds such as flavonoids, saponins, tannins, and caffeic acid phenethyl esters (CAPEs), which have antibacterial potential and anti-inflammation. ${ }^{7}$ The combination of calcium hydroxide and propolis as an intracanal medicament material has a potent antimicrobial effect compared with calcium hydroxide only. ${ }^{8}$ Other effect that expected is propolis able to inhibit the NF-kB, as the main target in the process of inflammation. ${ }^{9}$ Anti-inflammatory properties of these combinations, affect the immune system through phagocytosis activity and stimulate cellular immunity, so as to increase collagen type 1 which will affect the process of reparative dentin formation. Collagen type 1 is the main target that needs to be investigated as a provider of extracellular matrix for the process of reparative dentin formation. ${ }^{3}$ The many benefits of propolis provide the chief motive for the authors of this article to integrate natural and modern medicines. By combining calcium hydroxide with propolis as a pulp capping material, there is the hope that the superiority of each of these ingredients will overcome the shortcomings of other materials in current use.

\section{Materials and Methods}

\section{Animal}

This research has received an ethical eligibility certificate number: 167/HRECC.FODM/VIII/2017. The sample used the first molars of 60 rats with the following criteria: 8 to 16 weeks of maturity, a body weight of 200 to $300 \mathrm{~g}$, giving standard feed and drinking water ad libitum, perfect growth of first molar teeth, and giving feed consisting of BR 1 type chicken food mixed with one-part flour made into 15 to $40 \mathrm{~g}$ of pellets, daily.

\section{Tooth Preparation}

Equipment was disinfected with 95\% alcohol prior to the process. All rats were anesthetized with ketamine (Ketalar, WarnerLambert, Ireland). The occlusal surface of the teeth was cleaned with cotton pellets. Class I preparation (Black's classification) was made on the right maxillary molar using a handpiece (NSK Ltd., Japan) with a round bur, $0.46 \mathrm{~mm}$ in diameter (Edenta, Switzerland) at a low speed, until the pulp chamber was reached. After perforation, the cavity was cleaned with a drop of sterile saline solution and dried with cotton pellets.

\section{Propolis Preparation}

Propolis extract was prepared at Balai Penelitian dan Konsultasi Industri, Surabaya, East Java, Indonesia by treating dried Apis mellifera honeycomb (100\% propolis); as much as $1 \mathrm{~kg}$ was macerated and sliced to a thickness of 0.5 to $1 \mathrm{~cm}$.
Following this, $1,000 \mathrm{~mL}$ of $96 \%$ ethanol was added to the closed container and shaken at a speed of $80 \mathrm{rpm}$ for 24 hours to ensure the mixture was homogeneous and then filtered. The residue was evaporated using an evaporator vacuum at a temperature of 50 to $60^{\circ} \mathrm{C}$ to separate the propolis extract and the ethanol to obtain a thick consistency of the propolis extract with a concentration of $11.45 \%$. Finally, $11.45 \%$ propolis extract was diluted using sterile, distilled water until a concentration of $11 \%$ propolis extract was obtained. ${ }^{10}$

\section{Combination of Calcium Hydroxide and Propolis}

Calcium hydroxide was obtained by mixing pure calcium hydroxide powder with sterile aquadest at a ratio of 1:1 (0.9 g calcium hydroxide powder and $0.9 \mathrm{~mL}$ sterile aquadest). It was then stirred using a cement spatula on a glass slab until it formed a dough-like consistency.

The combination of calcium hydroxide and propolis was used by mixing calcium hydroxide powder and propolis extract with a ratio of $1: 2\left(0.6 \mathrm{~g} \mathrm{Ca}(\mathrm{OH})_{2}\right.$ powder and $1.2 \mathrm{~mL}$ propolis extract). ${ }^{11}$

\section{Application of the Combination of Calcium Hydroxide and Propolis}

After pulp chamber perforation in the right maxillary molar, the 60 rats were divided into six groups:

1. Group A: Control group. The pulp chamber is applied with Cention. Decapitation after 7 days.

2. Group B: Treatment group. The pulp chamber is applied with calcium hydroxide. Decapitation after 7 days.

3. Group C: Treatment group. The pulp chamber is applied with a combination of calcium hydroxide and propolis. Decapitation after 7 days.

4. Group D: Control group. The pulp chamber is applied with Cention. Decapitation after 14 days.

5. Group E: Treatment group. The pulp chamber is applied with calcium hydroxide. Decapitation after 14 days.

Group F: Treatment group. The pulp chamber is applied with a combination of calcium hydroxide and propolis. Decapitation after 14 days.After application, all right maxillary molars were restored with Cention. Rats were enclosed in cages and given standard food and water. All groups were euthanized by peritoneal injection according to the posttreatment time frame determined for each group. After decapitation, the jawbone in the interdental area of the maxillary first molar was removed.

\section{NF-kB and Collagen Type 1 Expression}

Histopathological preparations were completed using hematoxylin-eosin staining then observed using a light microscope (Nikon Corp., Japan) at $\times 400$ magnification. Additionally, immunohistochemical staining with polyclonal rabbit antibodies (Santa Cruz Biotechnology, Inc., United States) was performed to determine the expression of NF-kB and type 1 collagen. The NF-kB and collagen type 1 expression were analyzed in the pulp odontoblast cells. All analysis was conducted by a single operator in a blind procedure. 


\section{Statistical Analysis}

The results of the study were calculated as both mean and standard deviation and then analyzed using SPSS 24.0 for Windows. To determine the difference, the one-way analysis of variance test was performed and followed with the Tukey's honestly significant difference test with a significance level of 0.05 .

\section{Result}

A histopathological examination of anatomy in rat dental pulp odontoblast cells showed the morphology of odontoblast cells located in the peripheral part of the pulp chamber ( - Fig. 1).

\section{The NF-kB Expression}

The NF-kB expressed by the pulp odontoblast cells with 3,3'-diaminobenzidine staining appears as brown discoloration (-Fig. 2). Treatment with a combination of calcium hydroxide and propolis showed the highest NF-kB expression compared with calcium hydroxide only and Cention on days 7 and 14 (-Fig. 3 ).

The combination of calcium hydroxide and propolis exhibited a lower NF-kB expression, compared with calcium hydroxide only $(p=0.027)$ and Cention $(p=0.000)$ on day 7. Moreover, the NF-kB expression in the combination of calcium hydroxide and propolis was also lower, compared with calcium hydroxide only $(p=0.000)$ and Cention ( $p=0.000$ ) on day 14. Calcium hydroxide demonstrated a lower NF-kB expression than Cention on days 7 $(p=0.000)$ and $14(p=0.000)(-$ Fig. 3).

\section{The Collagen Type 1 Expression}

The collagen type 1 expressed by the pulp odontoblast cells with DAB staining appear as brown discoloration ( - Fig. 4). Treatment with a combination of calcium hydroxide and propolis showed the highest collagen type 1 expression compared with calcium hydroxide only and Cention on days 7 and 14 (-Fig. 5).

The combination of calcium hydroxide and propolis exhibited higher collagen type 1 expression compared with calcium hydroxide only $(p=0.001)$ and Cention $(p=0.000)$ on day 7 . Moreover, the collagen type 1 in the combination of calcium hydroxide and propolis was also higher, compared with calcium hydroxide only $(p=0.007)$ and Cention $(p=0.000)$ on day 14 . Calcium hydroxide demonstrated a higher collagen type 1 expression compared with Cention on days $7(p=0.003)$ and $14(p=0.001)(-$ Fig. 5).
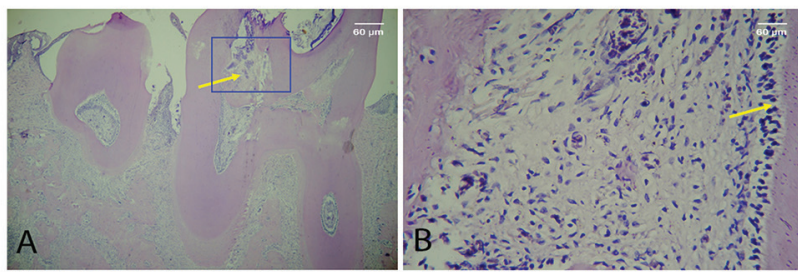

Fig. 1 The histopathology of the pulp chamber (magnification $\times 100$ ) (A). Histopathological morphology of odontoblast cells located in the peripheral part of the pulp chamber (yellow arrow) (magnification $\times 400)(B)$.

\section{Discussion}

The gold-standard pulp capping material in dentistry is calcium hydroxide because of its ability to stimulate mineralization, but it has the disadvantage of having the potential to irritate the pulp and cause inflammation. ${ }^{12}$ Several recent reports have indicated that calcium hydroxide has some disadvantages: it only sets in a dry environment, the dentinal bridges produced may have tunnel defects, and it is prone to dissolution over time. Research conducted by Brizuela et al (2017) shows that the failure of calcium hydroxide to maintain pulp tissue is only $13.64 \%$ compared with MTA. ${ }^{13}$ Concerns over the use of calcium hydroxide are regarding its physical characteristics; the report stated that calcium hydroxide has poor cohesive strength, greater solubility, and marginal leakage. ${ }^{14}$

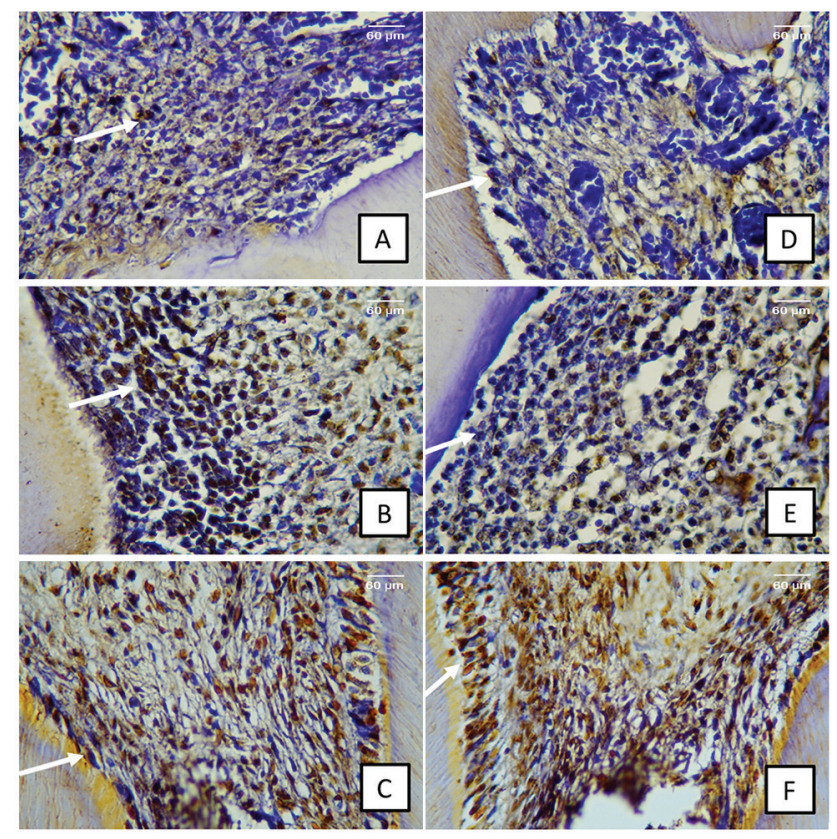

Fig. 2 The pulp odontoblast cells expressed NF-kB (white arrow). Treated with a combination of calcium hydroxide and propolis after 7 days (A) and 14 days (D). Treated with calcium hydroxide after 7 days (B) and 14 days (E). Treated with Cention after 7 days (C) and 14 days $(\mathbf{F})$. NF-kB, nuclear factor kappa B.

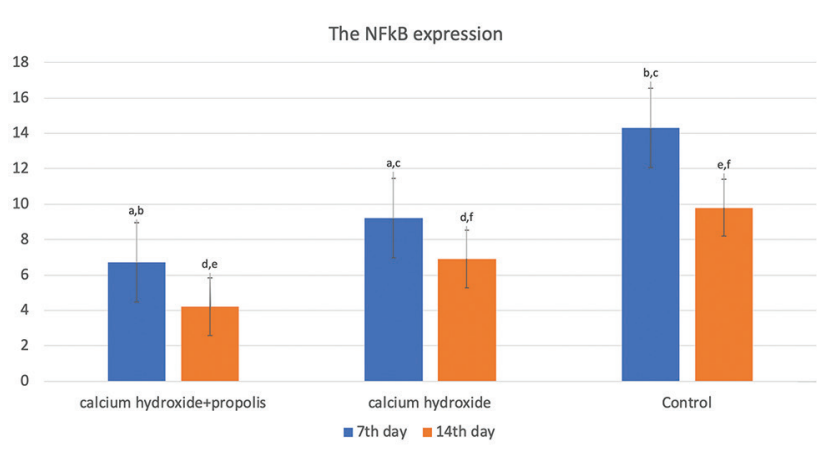

Fig. 3 The NF-kB expression after being treated with a combination of calcium hydroxide and propolis, calcium hydroxide only, and Cention. The same character on the top of the bar shows the difference in each treatment $(p<0.05)$. NF-kB, nuclear factor kappa B. 


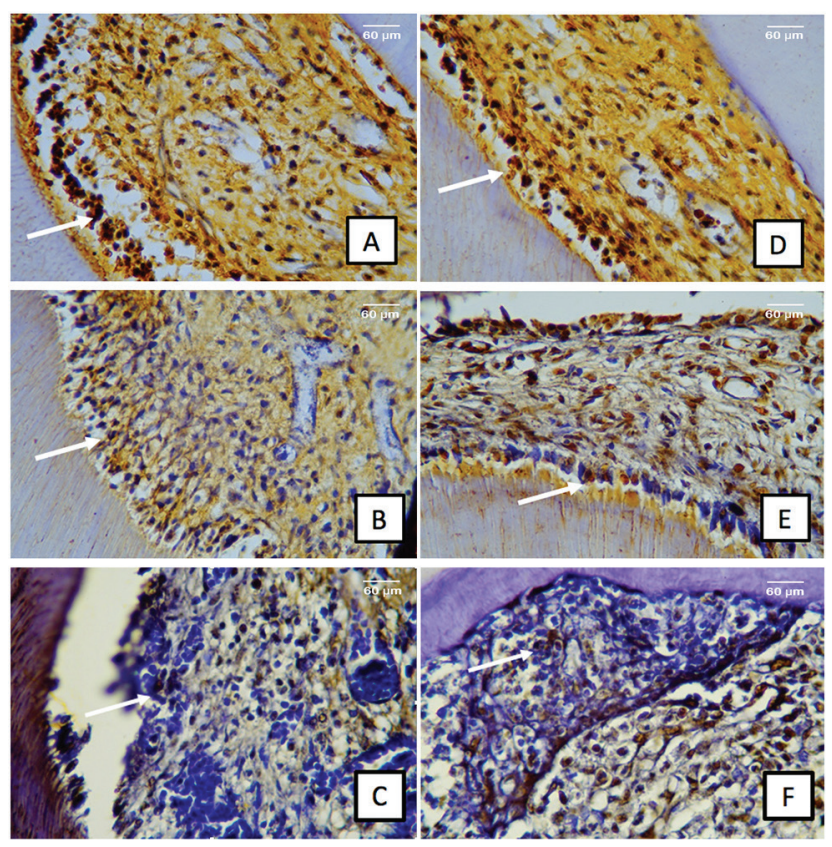

Fig. 4 The pulp odontoblast cells expressed collagen type 1 (white arrow). Treated with a combination of calcium hydroxide and propolis after 7 days (A) and 14 days (D). Treated with calcium hydroxide after 7 days (B) and 14 days (E). Treated with Cention after 7 days (C) and 14 days (F). NF-kB, nuclear factor kappa B.

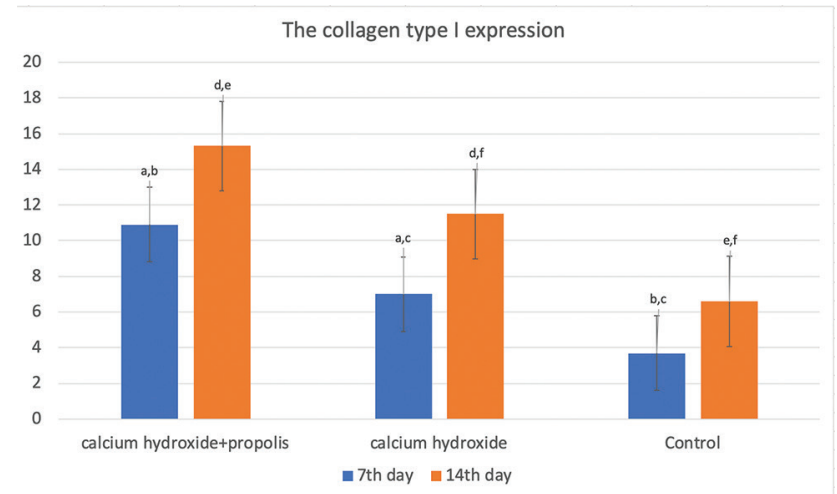

Fig. 5 The collagen type 1 expression after being treated with a combination of calcium hydroxide and propolis, calcium hydroxide only, and Cention. The same character on the top of the bar shows the difference in each treatment $(p<0.05)$.

Calcium hydroxide as a gold standard also has deficient in the formation of tunnel defects in the reparative dentin formation. This condition can cause the incomplete pulp filling and result in reinflammation, at least 3 months after treatment. ${ }^{15}$ To this condition, an alternative ingredient, combination of calcium hydroxide and propolis is needed. Propolis has anti-inflammatory properties which is expected to reduce inflammation than pure calcium hydroxide and to improve the physical characteristics of calcium hydroxide itself. ${ }^{15}$

Research on propolis has been widely performed both in vitro and in vivo, and the results demonstrate that propolis has several biological and pharmacological activities and is proven to be an anti-inflammatory agent. ${ }^{16}$ The anti-inflammatory properties of propolis are due to the presence of CAPE. Ethanol extract from propolis presents beneficial properties for endodontics, such as promoting bone regeneration and stimulating the formation of hard bridge tissue in pulpotomy or pulp capping. ${ }^{17}$ The anti-inflammatory properties of propolis are also caused by the presence of flavonoid compounds, amino acids, terpenes, and cinnamic acid derivatives. The mechanism of propolis in inhibiting inflammation is caused by inhibiting eicosanoid synthesis. This inhibition causes a decrease in the content of arachidonic acid in cell phospholipid membrane tissue, which further results in the inhibition of the release of several inflammatory mediators, such as prostaglandins, leukotrienes, and thromboxane. ${ }^{18}$ Based on previous explanations, the combination of calcium hydroxide and propolis to enhance the properties of calcium hydroxide is needed. In proof of this, in this study, we discovered that the NF-kB expression is lowest in the groups treated with a combination of calcium hydroxide and propolis compared with Cention and calcium hydroxide only on both days 7 and 14 . The possible mechanism for this condition is the role of ion $\mathrm{Ca}^{2+}$ and $\mathrm{OH}$ (hydroxyl ions) in the calcium hydroxide. Hydroxyl ions enter the cell through calcium channels and inhibit the phosphorylation of the inhibitor kappa $\beta$ and the activation of NF-kB. Inhibition of the NF-kB decreases the production of proinflammation, cytokine-like tumor necrosis factor $\alpha$ (TNF- $\alpha)$, interleukin 6 (IL-6), and interleukin $1 \beta$ (IL-1 $\beta)^{19,20}$ In open pulp, an inflammatory reaction occurs, characteristic of increased proinflammatory cytokines production, which causes a delay in the healing process. Treatment with calcium hydroxide will inhibit the NF-kB expression and reduce the production of cytokine proinflammation. ${ }^{21-23}$

The combination of calcium hydroxide and propolis showed lower NF-kB expression, compared with calcium hydroxide on both 7 and 14 days. This combination exhibited superior anti-inflammatory properties compared with calcium hydroxide only. Propolis not only inhibited NF-kB expression but also restored the expression of IL-1 $\beta$, IL-6, and TNF- $\alpha$ to a basal level. A further property of propolis is that it can interfere with other immune cells to produce cytokine. ${ }^{24}$

Calcium hydroxide has a high $\mathrm{pH}$ (alkali) and causes necrosis with a minimum depth of $1 \mathrm{~mm}$ on the surface area of the cell. When it comes into contact with the pulp tissue, it causes a decrease in cell proliferation, followed by a decrease in cell differentiation, resulting in a decrease of the formation of collagen type $1 .{ }^{25} \mathrm{~A}$ combination of calcium hydroxide with propolis can prevent this condition, as propolis can be the active component, CAPE. CAPE plays an important role in inhibiting the activation of NF- $\mathrm{kB}$ to produce the proinflammatory cytokines. ${ }^{26}$ The reduction of cytokines is likely associated with inhibition of the inflammation feedback loop as well as with decreased degradation of the extracellular matrix through the inhibition of matrix metalloproteinase expression, which plays a role in proteolytic activity. Moreover, propolis application has also shown upregulation of transforming growth factor (TGF)- $\beta$ gene expression and enhanced Smad2/3 phosphorylation. It has been established that TGF- $\beta$-induced proliferation of keratinocytes and fibroblasts leads to new formations of capillaries in the granulation tissue, modulated extracellular matrix deposition, and 
reconstitution of the injured area. ${ }^{24}$ The upregulation TGF- $\beta$ leads to increased activity of pulp cell proliferation and develops to form fibroblasts. Fibroblasts will differentiate to form odontoblast-like cells and increase the expression of collagen type 1 to replace damaged odontoblasts. ${ }^{27}$ This possible mechanism also explains the higher expression of collagen type 1 in the combination of calcium hydroxide with propolis compared with calcium hydroxide only.

The combination of calcium hydroxide with propolis is not only able to decrease the NF-kB expression and increase the collagen type 1 expression but also enhances the physical characteristics of calcium hydroxide itself.

\section{Conclusion}

Based on the results of this study, it can be concluded that a combination of calcium hydroxide and propolis inhibits pulp inflammation and stimulates regeneration through decreasing NF-kB expression and increasing type 1 collagen. This combination is promising as a new material for pulp capping.

\section{Conflict of Interest}

None declared.

\section{References}

1 Elsalhy M, Azizieh F, Raghupathy R. Cytokines as diagnostic markers of pulpal inflammation. Int Endod J 2013;46(6):573-580

2 Hozhabri NST, Benson MD, Vu MD, et al. Decreasing NF-KB expression enhances odontoblastic differentiation and collagen expression in dental pulp stem cells exposed to inflammatory cytokines. PLoS One 2015;10(1):e0113334

3 Widjiastuti I, Suardita K, Saraswati W. The expressions of NF-kb and TGFb-1 on odontoblast-like cells of human dental pulp injected with propolis extracts. Dent J (Majalah Kedokt Gigi) 2014;47(1):13-18

4 Kakarla P, Avula JSS, Mellela GM, Bandi S, Anche S. Dental pulp response to collagen and pulpotec cement as pulpotomy agents in primary dentition: A histological study. J Conserv Dent 2013;16(5):434-438

5 Nowicka A, Łagocka R, Lipski M, et al. Clinical and histological evaluation of direct pulp capping on human pulp tissue using a dentin adhesive system. BioMed Res Int 2016;2016:2591273

6 Hilton TJ, Ferracane JL, Mancl L; Northwest Practice-based Research Collaborative in Evidence-based Dentistry (NWP). Comparison of $\mathrm{CaOH}$ with MTA for direct pulp capping: A PBRN randomized clinical trial.J Dent Res 2013;92(7,Suppl):16S-22S

7 Chang H, Wang Y, Yin X, Liu X, Xuan H. Ethanol extract of propolis and its constituent caffeic acid phenethyl ester inhibit breast cancer cells proliferation in inflammatory microenvironment by inhibiting TLR4 signal pathway and inducing apoptosis and autophagy. BMC Complement Altern Med 2017;17(1):471

8 Madhubala MM, Srinivasan N, Ahamed S. Comparative evaluation of propolis and triantibiotic mixture as an intracanal medicament against Enterococcus faecalis. J Endod 2011;37(9):1287-1289

9 Choy KW, Murugan D, Leong XF, Abas R, Alias A, Mustafa MR. Flavonoids as natural anti-inflammatory agents targeting nuclear factor-kappa B (NFKB) signaling in cardiovascular diseases: a mini review. Front Pharmacol 2019;10(OCT) :1295
10 Ramanauskienė K, Inkènienė AM. Propolis oil extract: quality analysis and evaluation of its antimicrobial activity. Nat Prod Res 2011;25(15):1463-1468

11 Wardhani WP, Meizarini A, Yuliati A, Apsari R. Perubahan warna semen ionomer kaca setelah direndam dalam larutan teh hitam. Dentofasial 2010;9(2):123-129

12 Garcia JMQ Martins MD, Jaeger RG, Marques MM. Immunolocalization of bone extracellular matrix proteins (type I collagen, osteonectin and bone sialoprotein) in human dental pulp and cultured pulp cells. Int Endod J 2003;36(6):404-410

13 Brizuela C, Ormeño A, Cabrera C, et al. Direct pulp capping with calcium hydroxide, mineral trioxide aggregate, and biodentine in permanent young teeth with caries: A randomized clinical trial. J Endod 2017;43(11):1776-1780

14 Revathi N, Sharath CS. Merits and demerits of calcium hydroxide as a therapeutic agent: A review. Int J Dent Sci Res 2014;2(6B) :1-4

15 Mostafa NM, Moussa SA. Mineral trioxide aggregate (MTA) vs calcium hydroxide in direct pulp capping - literature review. Online J Dent Oral Heal 2018;1(2):1-6

16 Sabir A. The effect of propolis on cytokines during dental pulp inflammation. J Apic 2016;31(1):97-100

17 Neelakantan P, Jagannathan N, Nazar N. Ethnopharmacological approach in endodontic treatment: A focused review Prasanna. Int J Drug Dev Res 2011;3(4):68-77

18 Parolia A, Kundabala M, Rao NN, et al. A comparative histological analysis of human pulp following direct pulp capping with Propolis, mineral trioxide aggregate and Dycal. Aust Dent J 2010;55(1):59-64

19 de Moraes Costa MM, Penha de Oliveira SH, Gomes-Filho JE. Mechanism of calcium hydroxide-induced neutrophil migration into air-pouch cavity. Oral Surg Oral Med Oral Pathol Oral Radiol Endod 2008;105(6):814-821

20 Surboyo MDC, Mahdani FY, Ernawati DS, Sarasati A, Rezkita F. The Macrophage responses during diabetic oral ulcer healing by liquid coconut shell smoke: An immunohistochemical analysis. Eur J Dent 2020;14(3):410-414 doi:10.1055/ s-0040-1712776

21 Nirwana I, Agustantina TH, Soekartono RH. Nf-Kb expressions on rat dental pulp mechanically exposured after pomegranate fruit extract administration. J Int Dent Med Res 2017; 10(1):123-127

22 Surboyo MDC, Arundina I, Rahayu RP, Mansur D, Bramantoro T. Potential of distilled liquid smoke derived from coconut (Cocos nucifera $L$ ) shell for traumatic ulcer healing in diabetic rats. Eur J Dent 2019;13(2):271-279

23 Surboyo MDC, Mahdani FY, Savitri DS, et al. Number of macrophages and transforming growth factorßexpression in Citrus limon L. Tlekung peel oil-treated traumatic ulcers in diabetic rats. Trop J Pharm Res 2019;18(7):1427-1433

24 Hozzein WN, Badr G, Al Ghamdi AA, Sayed A, Al-Waili NS, Garraud O. Topical application of propolis enhances cutaneous wound healing by promoting TGF-beta/Smad-mediated collagen production in a streptozotocin-induced type I diabetic mouse model. Cell Physiol Biochem 2015;37(3):940-954

25 Kunarti S. Pulp tissue inflammation and angiogenesis after pulp capping with transforming growth factor $\beta 1$. Dent J (Majalah Kedokt Gigi) 2008;41(2):88-90

26 Wang LC, Chu KH, Liang YC, Lin YL, Chiang BL. Caffeic acid phenethyl ester inhibits nuclear factor-kappaB and protein kinase B signalling pathways and induces caspase- 3 expression in primary human CD4+ T cells. Clin Exp Immunol 2010;160(2):223-232

27 Lucchini M, Romeas A, Couble ML, Bleicher F, Magloire H, Farges JC. TGFß1 signaling and stimulation of osteoadherin in human odontoblasts in vitro. Connect Tissue Res 2002;43(2-3):345-353 